\title{
EXPLORING THE BELIEFS OF ACADEMIC SELF- EFFICACY AMONG UNDERGRADUATE MALE ENGINEERING STUDENTS
}

\author{
Touseef Fatima \\ Research Scholar, \\ Department of Education, SZABIST, \\ Sindh, Pakistan \\ Email: touseeffatima15@gmail.com
}

\section{Kiran Hashmi}

Assistant Professor,

Department of Education, Ziauddin University,

Sindh, Pakistan

Email: kiranhashme@gmail.com

\begin{abstract}
Self-efficacy entails the belief of an individual in oneself for the accomplishment of a specific task. The study investigated sources as well as perceptions that promoted the development of academic self-efficacy of undergraduates. The phenomenological pproach employed to analyze the perceptions of undergraduate male engineering students. As phenomenology found compatible with undergraduate students to explain their feelings, experiences, and thoughts about returning to obtain their engineering degree in university after being dropped out. Five participants from private Sindh chartered university responded through an adapted semi-structured interview that reflected their responses on the components of self-efficacy; (a) performance experience, (b) vicarious learning, (c) verbal persuasion, (d) affective states and physical sensation. The data was analyzed by thematization. The findings of the study suggested that components of self-efficacy were the strongest predictors for undergraduate male students who had been dropped out of university to eventually return to earn their engineering degree in university. Furthermore, the study also explored those perceptions about components of self-efficacy that provided a framework to learn those experiences that impact on the academic success of undergraduate male students who had dropped out of university to eventually return to earn their engineering degree in university.
\end{abstract}

\section{KEYWORDS}

Self-efficacy, Academic self-efficacy, Dropout, Agent of socialization 


\section{INTRODUCTION}

The acceleration of technological innovation and variation of social, political, environmental and economic situations have profound implications for the education system (Global Education Meeting 2018). Education is one of the significant constituents for social and economic achievements (Stuit, 2010). Thus the purpose lies behind the achievement of higher education degree in Pakistan are personal and instrumental in nature (Chan, 2016). This causes the hunger of getting admitted into tertiary level education (Higher Education and Employability, 2014). Thus, the enrollment rate in the under-graduate study has been reached to 1298600 in 20142015(HEC). Moreover, the numbers of graduates in the different degree-awarding institutions and universities have been recorded 220225 (HEC, 2016). However, the difference in getting in and successfully passed out rates from degree-awarding institutions and universities shows the lack of consistency and persistence. Consequently, consistency and persistence towards getting degrees need self-efficacy (Salami, 2010). The role of self-efficacy within the domain of academics has been shown positively significant with academic achievements (Bushra Akram, 2014).

A study revealed that while getting in the degree-awarding institutions and universities students not only have financial and academic barriers but also encounter doubts and fear of the completion of it (Tough, 2014). Students pursue their goal by accepting hurdles as challenges and improve their study habits and demonstrate flexibility in learning strategies through adapting changes according to change of environment (Elmotaleb, 2013). As the level of self-efficacy among students affects the amount of effort, they apply for difficult tasks consistently and persistently (Hibbs, 2012). Similarly, higher the self-efficacy lesser is the chance of giving up in difficulties (Ersanla, 2015). Thus, students of the undergraduate level need to spend quality time to meet academic expectations (Lichtenstein, 2010).

Researchers and educators have investigated several factors that developed students' retention and academic achievement in undergraduate engineering education (Brown, 2015). Students of undergraduate level meet several challenges due to more rigorous and challenging course work than their intermediate course work since engineering awarding institutes teach on the basis of Washington Accord signatory (PEC, 2019). Considering that engineering students need to explore their perception of competence and self-efficacy. Researchers found that the academic achievements of undergraduate engineering are positively significant with the engineering self-efficacy and success in engineering (Jones, 2010). Similarly, students' perceptions about their self-efficacy made them be retained in engineering programs (Geisinger, 2013).

The study will enhance the body of knowledge about academic self-efficacy and degree completion of undergraduate male students at the tertiary level of study. The 
findings of the study were significant for understanding the perception of undergraduate male students. The number of literature found the relationship between self-efficacy and academic achievement, on the contrary sources of self-efficacy in academic pursuit have been ignored. Similarly, a large number of classroom strategies have been identified to improve students' academic efficiency while lesser efforts have been exerted to enable students to sustain their efforts towards their graduation. Moreover, the study will boost the confidence of those who want to stand out and perform actions for improving the productivity and employability of the students. Additionally, the incorporation of academic self-efficacy into the undergraduate program will enhance students' retention and graduation from the tertiary level of education.

\section{LITERATURE REVIEW} Academic self-efficacy

Self-efficacy is considered as the most important and reliable predictor of university student achievement. Self-efficacy has been found to strongly correlate with university grade point average (GPA) from amongst several measures like; personality traits, motivational factors, self-regulatory learning strategies, students' approaches to learning, and psychosocial contextual influences (Richardson, 2012). Recently higher education researcher has attempted to research on students' approaches to learning (Trigwell, 2013). The concept of children's motivation and achievement at school explored by Dale Schunk that began the study of self-efficacy in the formal education system(Patterson-Hazley, 2013). At earlier, it was highlighted as a behavioral modification predictor whereas now the construct of self-efficacy has been giving much attention in the educational context. Several pieces of research have been performed at different levels (primary, secondary and tertiary) along with various areas of study (reading, writing, arithmetic, computing) to establish the relationship between self-efficacy and achievement (Mart van Dinther, 2011).

\section{Academic self-efficacy at Tertiary level of study}

The concept of self-efficacy has been explored through several researchers at the tertiary level. A study in the UK about completion of tasks found first-year psychology undergraduates completed an optional study skills program successfully (Macaskill, 2013). Similarly, a high level of self-efficacy found in fifth-year veterinary students of Belgium who were guided in a class learning activity (Govaere, 2012). Another study in Turkey using Inventory Student Survey found academic self-efficacy highly correlated with academic performance (Balkis, 2013). A study to investigate college student's development in general and academic achievement among Mexican Americans found academic self-efficacy strong predictor for academic performance (Avalos, 2017). An intervention design study in the Netherlands found that changes in students' self-efficacy level lead to a change in academic performance (Schaufeli, 
2013). A study about STEM education carried out in minority students of USA found student's self-efficacy for learning and performance in the course correlated with grades while self-regulated learning had no correlation with grades (Jackso, 2018). Similarly, several cross-sectional studies on African Americans found self-efficacy significantly correlated with performance (DiBenedetto, 2011). Additionally, another cross-sectional study in Norway raised that self-efficacy is positively correlated with exam grades (Diseth, 2011). In addition to the cross-sectional study on self-efficacy in Egypt found a path of statistically significant relationship which begins with selfefficacy moves forward to metacognition to effort regulation and reaches to academic performance (Kassab, 2015). Likewise, the cross-sectional study in Iran using the Selfefficacy belief scale marked self-efficacy significant to academic performance (Pouratashi, 2013). Another research attempted to find the level of academic selfefficacy in Malaysian adolescence and found level of academic self-efficacy has been influenced by socioeconomic background, varied academic setting and gender differences(Agnes Indra Chokkalingam, 2016)

A non-class experimental task has been carried out among the first-year undergraduate in introductory JAVA computer programming in Taiwan, found that the experimental group undertakes remedial learning after knowledge (Chen, 2011). In the same way, another non-class experimental task has been carried out among third-year undergraduates in Taiwan who were majoring in Management Information System were found that the group with guidance has a high level of self-efficacy (Shaw, 2010).

\section{Academic Self-efficacy at Tertiary level of Study in Sub-continent}

In the same way, undergraduate students in many countries found a significant role in academic self-efficacy in their academic achievement. A cross-sectional study in Bangladesh on the relationship between educational self-efficacy and educational motivation in the field of Medical education found that a significant number of students have shown high academic self-efficacy with educational motivation (Maryam Maraghi, 2016). Another study in Bangladesh found high achievers of school students differed from the low one based on organization, self-regulation, and metacognition (Oli Ahmed, 2015). Similarly, a study in India investigated the impact of self-efficacy on the psychological well-being of male and female undergraduate students and found a significantly different impact of self-efficacy on the psychological well-being of male and female undergraduate students (Siddiqui, 2015). While in the context of academic self-efficacy undergraduate female students of India in the computing field found to have more self-efficacy as they imagined about future consumptions of their learning in their life (Varma, 2010).Additionally, a study in Pakistan revealed that academic performance in form CGPA of undergraduate students from the faculty of Social and Basic Sciences had a significant correlation with academic self-efficacy (Bushra Akram, 2014). Furthermore, another study in Pakistan found that academic 
achievement of Science students in Mathematics was highly correlated with academic self-efficacy (Sadaf Naz, 2016). However, most studies are of quantitative in nature that made the present study to explore perceptions that promoted the development of academic self-efficacy of undergraduate male students at the tertiary level of study who had and eventually return to earn their engineering degree in university.

\section{Theoretical Framework of the study}

The study is based on the belief of self-efficacy emerges from Social cognitive theory. As the belief of an individual in himself for the accomplishment of a specific task is referred to as self-efficacy(Bandura A., 1997).The belief of self-efficacy is more task and situation-specific that makes the self-efficacy belief different from other expectancy beliefs (Pajares, 1996). Additionally, self-efficacy is assessed at a microanalytical level while potency, self-esteem and other expectancy are multifaceted and generalized concept .For example, a self-efficacy instrument investigates a student's confidence over a particular task while self-esteem asks about one's positive evaluation (Bandura A., 2012). The concept of self-efficacy as postulated by Bandura (Bandura A., 1977) are developed and influenced by five sources of information that are enactive mastery, vicarious learning, verbal persuasion, affective state and physical sensation and imaginal performance. The theoretical framework of the study is based on academic self-efficacy that covers enactive mastery, vicarious learning, verbal persuasion, affective state, and physical sensation and imaginal performance as dependent determinants and agents of socialization are independent determinants.

\section{RESEARCH OBJECTIVES}

1. To investigate sources that promoted the development of academic self-efficacy of undergraduate male engineering students.

2. To explore perceptions that promoted the development of academic self-efficacy of undergraduate male engineering students.

\section{RESEARCH QUESTIONS}

1. What sources of self-efficacy do undergraduate male students at the tertiary level of study develop to foster academic self-efficacy?

2. How do undergraduate male students at the tertiary level of study describe their experience to foster academic self-efficacy?

\section{RESEARCH METHODOLOGY}

The present study will use qualitative research methods. In order to explore and enhance the knowledge of a problem, qualitative research is conducted (Creswell, 2013). The in-depth examination of a particular context and reporting comprises the voices of participants with the explanation of the issue that ultimately calls for change (Creswell, 2013). As the purpose of the present study is to explore the lived 
experiences of engineering university students, qualitative research with phenomenology was chosen. Since phenomenological research investigates a description of a first-person perspective (Creswell, 2014). The inquiry method is quite appropriate as the study will explore the phenomena, self-efficacy and its influence in the lives of undergraduate male students at the tertiary level of study who had dropped out and had not dropped out of university to eventually return to earn their engineering degree in university. As phenomenology does not explain phenomena but wants to establish an understanding of how phenomena come from consciousness through the examples of participant surrounding and encountering. The end of phenomenology is to give insight to the description of perception and experiences of the individuals being studied by analyzing the component of self-efficacy including physiological and psychological responses to experiences, observations of others, and self-consciousness (Smith, 2013).

The study started with an exploration of the contribution of the construct of selfefficacy in the success of undergraduate male students at the tertiary level of study who had dropped out and eventually return to earn their engineering degree in the university through their lived experience while enrolled in private engineering university. The prescribed steps of conducting phenomenology were used in the study. Firstly the researcher explained the research topic consequently moved by literature review of the subject matter to encompass general understanding of undergraduate students who had dropped out to eventually return to earn their engineering degree in university through their lived experience while enrolled in private engineering university their persistence and success. Secondly, a purposeful convenience sample population was chosen. Next, the lived experiences of the sample population were collected through an informal meeting and one follow up interview. Then, the four rounds of data analysis of lived experiences were carried out. Afterward, findings were represented through a written synthesis. Then, the researcher will substantiate the written synthesis with the addition of the lived experience of the phenomenon, which the participants were unaware of. The step was followed by an in-depth literature review focused on the phenomenon. Finally, the varying elements of self-efficacy experienced by the participants were jolt down in written form.

\section{Population}

The population for the present study involved private engineering university students represented through a purposeful convenience sampling of being a dropout and regular students. Participants in the present study were selected by primary contacts. The researcher will gain access to the participants through informed consent. Because it is necessary that the selected participants in the sampling have experienced the phenomenon being studied (Creswell, 2013).Additionally, the sample size would be 
five private engineering undergraduate university students and selection of the participants will meet the following criteria:

1. Left engineering university before graduating

2. Then come back to another engineering university further continued to study towards a higher education degree in engineering.

\section{Data collection}

In the words of Pietkiewicz and Smith, an interpretative phenomenological analysis primarily dewith drawing out rich, detailed and first-person descriptions of experiences of the phenomenon under investigation (Pietkiewicz, 2014). A semi-structured interview was used as the primary instrumentation. Semi-structured interviews will allow the participant to participate in real-time with the researcher while also engaging space and flexibility to further investigate and obtain necessary details (Pietkiewicz, 2014). The interview protocol was adapted from Dr. Deniece Dortch's work entitled "The Strength from Within: A Phenomenological Study Examining the Academic Self-Efficacy of African American Women in Doctoral Studies (Dortch, 2016)". After the completion of each interview, the researcher will transcribe the interviews verbatim. The researcher will proofread the transcriptions of the interviews. Furthermore, thematic analysis was carried out for data analysis. The interview questions were aligned to the research questions in this study. The questions were standardized and open-ended to let the participants recount their experiences fully. Moreover, using the semi-structured interview protocol will allow the researcher for standardization to acquire similar information from each of the participants, while also allowing for flexibility during the interview process. The order of the questions was stayed the same during each of the interviews to remain focused on the experience of belief of self-efficacy. Jet University (JU; a pseudonym), predominantly recently wellknown engineering institution for a middle-class family in an urban city in Karachi as a university offering a variety of programs in fewer market fees, having high enrollment rate including students from urban and rural areas too has been selected as a research site. There are $80 \%$ of students who are from rural areas including interior provinces of Pakistan. Jet University offered various undergraduate degrees in different disciplines. The university has successfully accredited its different programs by accredited institutions of the country. Moreover, the faculties of the university in most of the departments are from the interior provinces of Pakistan. Most of the faculty lives without their family in the city as well as students also live without their family. The university does not offer any affiliated accommodation to the faculty and to the students as well. The infrastructure of the institution is quite congested while wellequipped. In addition to this, most students and faculty are regional bilingual speakers. The transport facility has also been managed by the faculty and students for themselves. 


\section{Sampling}

Five undergraduate male students from the Department of Electrical Engineering -Ali, Farooq, Usman, Umer and Bilal (pseudonyms) participated in the study. A purposeful convenience sample has been chosen as it is compatible with a phenomenological study due to providing an in-depth understanding of each participant's lived experiences (Patton, 2005). The participants were selected while considering their track record of study, racial identification, regional identification, socio-economic background and full-time undergraduate students at Jet University. Ali, a student of bachelor in engineering, currently is in his second year and third semester of his BE program and he took admission in Jet University immediately after leaving the another private engineering university at Karachi. Farooq, another student of bachelor in engineering, is also in his second year and third semester of his BE program and he took admission in Jet University immediately after leaving Bachelors program the another private engineering university of Karachi. Usman, another student of bachelor in engineering, is in his third year and the fifth semester of his BE program and he took admission in Jet University after leaving Bachelors program in the some other public university of Islamabad. Umer, another student of bachelor in engineering, is in his third year and the fifth semester of his BE program and he took admission in Jet University after leaving Bachelors program in the some other public university of Islamabad. Similarly, Bilal, another student of bachelor in engineering, is in his third year and the fifth semester of his BE program and he took admission in Jet University after leaving Bachelors program in the some other private university of Karachi..

\section{RESEARCH FINDINGS}

After the selection of five participants from a private engineering university, they were asked to meet on campus and interviewed. The 35 to 45 minutes interview was recorded and took notes of participants' responses. At the end of every interview, the participants were acknowledged for their time and responses. Similarly, they were asked to share their views about their state of mind after interviewing as well as about the quality of information that was provided by them. Then, each interview was transcribed.

After that, in the first stage, the interview transcriptions were given the number to each fragment of every interview one by one. In the second stage, interview transcriptions were read multiple times and came up with the emerging sub-codes of the data. Then, in the third stage, the researcher returned to the code and assigned the color to each code in every transcription. In the fourth stage, the researcher returned to the transcript and jolt down the sub-codes into the cluster and came up with the emerging sub-codes. At the final stage, a table of sub-codes and quotes to depict the lived experiences of the sample was created. 
The findings of the study revealed that the navigation of self-reliance, bending towards family reciprocity and the quest for social support was evident from the responses. The concept of self-reliance made the participants to monitor and control their behavior and performances to prevent avoidance behavior and become persistence in their choices. In the words of Pajares, individual communicates and change their environmental and personal factors as well as these factors also change and communicate them too (Pajares, 2005). A study consisted of focus groups indicated students' self-concept in their way to success in college (Dogan, 2015). Thus in the current study participants were found to be communicated and changed by their personal and environmental factors.

The inclination towards family reciprocity is evident from the findings as it mentions the parental role, family member role in their relationship with the participants. The give and take relationship between participants and their family members made them rejoin university and pursue them to choose the same field. The success and failures of others influence individuals' belief in their capability (Pajares, 2005). A qualitative study found that parents were providing the facilitation to enable the students to learn in a safe environment as both were benefitted by achieving the degree (Bergen, 2013). The social support is evident from the current study. The teachers, peers, and friends support the participants to be persisted in his choice of pursuing an engineering degree. The findings of the current study support the pieces of evidence that show the support of social members including teachers, peers and friend enable the individuals to approach rather than avoid certain behavior (Corkett, 2011). The factor to discuss their problem with someone prevent individuals from stress and fatigue (Brackett, 2010). Moreover, the Triadic Reciprocal explains personal attributes affect their behavior and their selection of choices (Bandura A., 1986). The sources that were researched by Bandura are enactive mastery, vicarious learning, verbal persuasion, affective state, and physical sensation and imaginal performance. The participants of the current study mentioned that they are affected by the way their parents, family members, teachers, and friends act, the thing the parents, family members, teachers, and friends say and interact. These affected behaviors are thematized into the navigation of self-reliance, bending towards parental reciprocity and the quest of social support and signify that the participants of the current study experience enactive mastery, vicarious learning, and verbal persuasion.

Additionally, the findings of the study show learning for the sake of earning of the participants. The eventual return to the University of the Participants is made them get the degree for getting a job in the future. The instrumental motivation for returning to a degree is evident. The future goal enables one to take immediate action and pursue them to achieve the goal (Herrera, 2009). Moreover, the behavior of the participants was also customized by their interaction with society. They found to be engaged in 
engineering as it would be made them be accepted in society. These acceptance offered participants to develop academic self-efficacy in the study. The cultural norms compelled individuals to mold their behavior and conform to the cultural norms by guiding how to behave in a particular culture (McLeod, 2008).

\section{Epoché}

For managing the current study free from personal subjectivity. The bracketing was applied to acknowledge the subjectivity of the researcher. The researcher wrote reflective notes after reading each interview. Then peer review of the reflective notes was carried out after listening to the interview. Similarly, the reflexivity was also approached by reviewing the peer review comments and made changes for the sake of avoiding the inclusion of personal biases to interpretation.

\section{Trustworthiness}

For ensuring the validity of the study Creswell's validation strategies (Creswell, 2007) were followed. Firstly, an external check of the phenomenological process was carried out by peer review. Secondly, the researcher bias was clarified onset of the study by elaborating the assumptions about the study and acknowledging the subjectivity. Thirdly, after the transcription of each interview, the participants were asked to read the transcription. In the end, the rich description through students' narratives, the research became transferable.

\section{DISCUSSION}

\section{Mastery of Experiences}

Self-efficacy explains how people face failures and describes that those with a high degree of efficacy perceive setbacks as challenges to overcome (Bandura A., 1997). Success facilitates to enhance a strong sense of self-efficacy, while failure lowers it. Usman and Umer passing their two courses in the second attempt to improve their selfefficacy. Ali, Farooq, and Bilal took admission to another university and successful moving towards their degree completion.

The belief of self-efficacy influenced motivations to learn and persist (Zimmerman, 2000). None of the participants expressed any hostile environment in the current university. While they expressed that the last university environment was not providing support to let them continue their degree there (Shorter-Gooden, 2004). The non-supportive behavior of faculty left them in a hostile environment in and outside the campus. It resulted in fatigues, this fatigues is a diversity of institution that is related to challenges of the institution (Shorter-Gooden, 2004)

\section{Vicarious Experience}

The observation of others and the learning that took place as a result of hearing and 
knowing of other people's experiences (Bandura A., 1997). Several experienced by each participant that illustrated how influential the experiences of others considered important in their approach to completing the difficult and different tasks. When participants of the study were feeling the pressure in any difficult task, they found helpful to learn that they have different sources to learn from. Similarly, participants also compare themselves to other members of the society. As they found that their current classmates are also weak in some subjects as they are also. Then they overcome their difficulty (van Dinther, 2011).

\section{Verbal Persuasion}

The evaluative feedback is most successful when the information is well-informed, reliable and pragmatic (van Dinther, 2011). The individual self-efficacy improves by positive verbal interaction. In the case of every participant, that how the positive feedback from faculty and family member develop their self-efficacy. Furthermore, the verbal feedbacks that each participant received supported their self-efficacy (van Dinther, 2011). To conclude, persuasive communication from faculty, family and friend have the strength to serve as strong motivation to the success of the students (van Dinther, 2011).

\section{Physiological Responses}

The physiological responses that are experienced in response to pursue difficult task (Bandura A., 1997). The negative emotions can be interpreted as a sign of failure, while positive moods can strengthen one's self-efficacy (Pajares, 1996). The participants expressed having anxiety around their experiences while dealing with subject difficulty and asking favors from faculty. They found low self-efficacy in their last university. The lower self-efficacy results in hindrance to their academic success (Zimmerman, 2000). Many undergraduate students attending those courses that let them in a dire situation (Pečujlija, 2012)The increased self-efficacy of undergraduate students is depended on a clear and safe environment where students deliberately share their shortcomings and show their desire to overcome them.

\section{Conclusion and Recommendations}

The current study was attempted to explore the experience of undergraduate engineering students who dropped university and eventually return to a higher education degree. The findings of the study can be employed as a guide to limit the dropout rate of undergraduate students. The following conclusions from the data are drawn: (a) realized their shortcomings and improve them by eventually return to tertiary level of study (b) instrumental motivation played an important role in the returning of undergraduate engineering university (c) social support boost their selfreliance level to rejoin the undergraduate program in another university (d) avoidance 
of standing against the cultural norms and (e) conformity of social group for the sake of belongingness.

To investigate the sources of self-efficacy that undergraduate male engineering student develops to foster academic self-efficacy found that the students develop self-efficacy in pursuing engineering field even after being dropped out. The shreds of evidence are consistent with Bandura's social cognitive theory (Bandura A., 1997). These pieces of evidence assert that past experiences enable students to develop self-efficacy. Mastery of experience has become an apparent and potential source of self-efficacy in the current study. When participants of the study found their shortcomings and realized that they need to improve and improved as well, thus they develop a robust belief in their self-efficacy (Bandura A., 1977).

The current study suggests that the strategies primarily employed by undergraduate engineering students for fostering their academic self-efficacy are social support, instrumentally motivated and pressure of cultural conformity. In understanding and recognizing the pivotal role, that mastery of a task, vicarious experience, verbal persuasion, and physiological responses have on the intersection of the undergraduate students. Moreover, realizing undergraduate students' self-efficacy and its impact on persistence also facilitate administrators to unlade how undergraduate engineering students experience academic self-efficacy.

Future research on the current topic would be favorable for both scholars and practitioners to gain insight into the self-efficacy of undergraduate students and its influence on undergraduate students of the tertiary level. The nation-wide multidisciplinary study consists of other disciplines of the undergraduate program and also the public sector tertiary level of study too. It would also be investigated vicarious experience and verbal persuasion are the prevailing factor of self-efficacy for undergraduate humanities, medicine and management disciplines. Similarly, a large sample size would be studied to understand whether self-efficacy is also informed by the norms that are found in the disciplines. Additionally, the findings of the current study also concluded will facilitate practitioners and others invested in their upcoming generation as well want to transfer the lessons learned to other dropped out students of tertiary level.

\section{RECOMMENDATIONS}

The tertiary level of administrators and other professionals pursuing to minimize their dropout rate should acknowledge social support along with institutionalizing support system that considers the experiences of undergraduate engineering students who left university and eventually returned to complete their degree. To all of the tertiary level of study consult to establish student support mechanism that enables tertiary level 
students to foster academic self -efficacy. The student support mechanism provides not only guidance but also offers mentorship to control and cope with study stresses. The mentors can serve undergraduate students as an advisor, motivators, counselor, facilitator to let them learn their rights and duties.

\section{REFERENCES}

Agnes Indra Chokkalingam, P. A. (2016). An exploration of the level of academic selfefficacy (ase) among malaysian adolescents based on socioeconomic, different academic settings and gender. Journal of Education and Social Sciences , 5 (2), 8694.

Avalos, M. R. (2017, May). College Self-Efficacy and Academic Performance in Mexican American Undergraduates. College Self-Efficacy and Academic Performance in Mexican American Undergraduates . Arizona state university.

Balkis, M. (2013). The relationships between Academic procrastination and Students' burnou. H.U. Journal of Education, 28 (1), 68-78.

Bandura, A. (2012). On the functional properties of perceived self-efficacy revisited. $J$. Manag, 9-44.

Bandura, A. (1997). Self-efficacy: The exercise of control (1st ed.). New York: NY: Worth Publishers.

Bandura, A. (1997). Self-efficacy: The Exercise of Control. Newyork: Freeman \& Company.

Bandura, A. (1977). Self-efficacy: Toward a unifying theory of behavioral change. Psychology Review, 191-215.

Bandura, A. (1986). Social foundations of thought and action: A social cognitive theory. Englewood Cliffs, NJ: Prentice Hall.

Bandura, A. (1977). Social Learning Theory. New York: General Learning Press.

Bergen, A. (2013). Self-efficacy, special education. . Bergen, A. (2013). Self-efficacy, special education. InSight: Rivier Academic Journal.

Brackett, M. P.-K. (2010). Emotion-regulation ability, burnout, and job satisfaction among British secondary-school teachers. Psychology in the Schools , 47 (4), 406-417.

Brown, P. R. (2015). The use of motivation theory in engineering education research: A systematic review of literature. European Journal of Engineering Education , 186205.

Bushra Akram, L. G. (2014). Self efficacy and academic performance of the students of gujrat university, pakistan. Academic Research International , 5 (1), 283-290.

Chan, R. Y. (2016). Understanding the purpose of higher education: An analysis of the economic and social benefits for completing a college degree. 6 (5).

Chen, L.-H. (2011). Enhancement of Student Learning Performance Using Personalized Diagnosis and Remedial Learning System. Computers and Education, 289-99.

Creswell. (2007). Research design: Qualitative, quantitative, and mixed methods approaches (2nd ed.). Thousand Oaks, CA: Sage: CA: Sage.

Corkett, J. H. (2011). Student and teacher self-efficacy and theconnection to reading and writing. Canadian Journal of Education, 31 (1), 65-98. 
Creswell, J. W. (2013). Qualitative inquiry \& research design: Choosing among five approaches. Thousand Oaks, CA: Sage.

Creswell, J. W. (2014). Research design: Qualitative, quantitative, and mixed methods approaches (4 ed.). Thousand Oaks, CA: Sage.

DiBenedetto, M. K. (2011). Within the pipeline: self-regulated learning and academic achievement among college students in science courses. American educational research association. New Orleans, LA.: American educational research association.

Diseth, A. (2011). Diseth, A. (2011). Self-efficacy, goal orientations and learning strategies as mediators between preceding and subsequent academic achievement. Learning and Individual Differences , 21, 191-195.

Dogan, U. (2015). Student engagement, academic self-efficacy, and academic motivation as predictors of academic performance. Anthropologist, 553-561.

Dortch, D. (2016). The Strength from Within: A Phenomenological Study Examining the Academic Self-Efficacy of African American Women in Doctoral Studies. The Journal of Negro Education , 85 (3), 350-364.

Elmotaleb, M. a. (2013). The role of academic self-efficacy as a mediator variable between perceived academic climate performance and academic performance. Journal Education and Learning , 2 (3).

Ersanla, C. Y. (2015). The relationship between students' academic self-efficacy and language learning motivation: A study of 8 th graders . Procedia - Social and Behavioral Sciences , $472-478$.

Geisinger, B. N. (2013). Why they leave: Understanding student attrition from engineering majors. International Journal of Engineering Education , 914-925.

Govaere, J. A. (2012). Differential Impact of Unguided Versus Guided Use of a Multimedia Introduction to Equine Obstetrics in Veterinary Education. Computers and Education , 1076-84.

HEC. (2016, January 30). Retrieved October 25, 2019, from Graduates Having Having 16 Years Of Education And Above From Universities Campuses And Affiliated Colleges Including Distance Learning (PROVISIONAL): https:/www.hec.gov.pk/english/universities/Pages/AJK/Graduates-16-years.aspx

Hibbs, D. (2012). An Investigation of the Self-Efficacy Beliefs of Black and Hispanic Students that have Experienced Success or Failure in Mathematics. Doctoral dissertation .(2014). Higher Education and Employability. British Council.

Herrera, D. (2009). Instrumental motivation is extrinsic motivation: so what?? Psychologica, 21-40.

Jackso, C. R. (2018). Validating and Adapting the Motivated Strategies for Learning Questionnaire (MSLQ) for STEM Courses at an HBCU. AERA Open , 4 (4), 1-16.

Jones, B. D. (2010). An analysis of motivation constructs with first-year engineering students: Relationships among expectancies, values,achievement, and career plans. Journal of Engineering Education , 319-336.

Kassab, S. E.-S. (2015). Relationships between the quality of blended learning experience, self-regulated learning, and academic achievement of medical students: a path analysis. Advances in Medical Education and Practice , 27-34.

Lichtenstein, G. M. (2010). Comparing the undergraduate experience of engineers to all other majors: Significant differences are programmatic. Journal of Engineering Education 

, 305-317.

Macaskill, A. a. (2013). Developing Autonomous Learning in First Year University Students Using Perspectives From Positive Psychology. Studies in HigherEducation , 38 (1), 124-42.

Mart van Dinther, F. D. (2011). Factors affecting students' self-efficacy in higher education. Educational Research Review , 95-108.

Maryam Maraghi, S. A.-T. (2016). The relation of educational self-efficacy and motivation among Medical Education Students. Journal of Advances in Medical Education (JAMED) , 1-8.

McLeod, S. A. (2008). Social roles. Retrieved December 10, 2019, from Simply Psychoogy: https://www.simplypsychology.org/social-roles.html

PEC. (2019, October 14-15). 2nd PEC Deans Conference. International Conference on Globalization of Engineering Education and Practices. Islamabad: PEC.

Oli Ahmed, M. K. (2015). Strategies For Learning And Academic Achievement Of Secondary School Students. Dhaka Univ. J. Biol. Sci. , 24 (1), 91-97.

Pajares. (2005). Self-efficacy and self-concept beliefs: Jointly contributing to the quality of human life. International advances in self-research , 95-121.

Pajares, F. (1996). Self-Efficacy Beliefs in Academic Settings. American Educational Research Association , 66 (4), 543-578.

Patterson-Hazley, M. a. (2013). Conversations with Four Highly Productive Educational Psychologists: Patricia Alexander, Richard Mayer, Dale Schunk, and Barry Zimmerman. Educational Psychology Review , 25 (1), 19-45.

Patton, M. Q. (2005). Qualitative research. Hoboken, NJ: Wiley.

Pečujlija, M. \&. (2012). Why we believe the computer when it lies. Computers in Human Behavior , 143-152.

Pietkiewicz, I. \&. (2014). A practical guide to using interpretative phenomenological analysis in qualitative research psychology. Czasopismo Psychologiczne-Psychological Journal , 20 (1), 7-14.

Pouratashi, M. Z. (2013). Effects of agricultural students' self-efficacy beliefs and test anxiety on their achievement motivation and academic performance. New Educational Review , 34 (4), 85-98.

Sadaf Naz, M. I. (2016). A Study of Students' Self-Efficacy and Academic Achievement in Mathematics at University Level. Journal of Arts and Social Sciences, , 1-20.

Salami, S. O. (2010). Emotional intelligence, self efficacy, psychological well-being and students' attitudes: implications for quality education. European Journal of Educational Studies , 2 (3).

Schaufeli, E. O. (2013). Believe, and You Will Achieve: Changes over Time in Self-Efficacy, Engagement, and Performance. Applied Psychology: Health And Wellbeing , 5 (2), 225-247.

Shaw, R.-S. (2010). A Study of Learning Performance of e-Learning Materials Design with Knowledge Maps. Computers and Education , 253-64.

Shorter-Gooden, K. (2004). Multiple resistance strategies: How African American women cope with racism and sexism. . Journal of Black Psychology , 406-425.

Siddiqui, S. (2015). Impact of Self-Efficacy on Psychological Well-Being among Undergraduate Students. The International Journal of Indian Psychology, 2(3), 5-16 
Smith, D. (2013). Phenomenology: The Stanford encyclopedia of philosophy.

Stuit, D. A. (2010). California's high school dropouts: Examining the fiscal consequences.

Trigwell, K. P. (2013). Evoked Prior Learning Experience and Approach to Learning as

Predictors of Academic Achievement. British Journal of Educational Psychology, 83 (3), 363-78.

Van Dinther, M. D. (2011). Factors affecting students' self-efficacy in higher education. Educational Research Review , 95-108.

Varma, R. (2010). Computing Self-efficacy Among Women in India. Journal of Women and Minorities in Science and Engineering , 16, 257-274.

Zimmerman, B. J. (2000). Self-efficacy: An essential motive to learn. Contemporary Educational Psychology, 25, 82-91. 